\title{
A análise harmônica tonal à luz do determinismo linguístico: uma proposta de análise harmônico-funcional do Lied Laß dich nur nicht dauern de Max Reger
}

\author{
Carlos Alberto Faísca Fernandes Gomes
}

22 outubro de 2019

(ङ®) $\odot$

\section{Sumário}

1 Introdução $\quad 2$

2 O determinismo linguístico $\quad 5$

$\begin{array}{llr}3 & \text { Simbologia analítica } & 7\end{array}$

4 Exemplo de análise harmônica $\quad 9$

5 Conclusão $\quad 12$

$\begin{array}{ll}\text { Referências } & 13\end{array}$

\section{Resumo}

No presente artigo discuto alguns aspectos relacionados com o uso de cifras harmônicas aplicadas à análise harmônico-funcional, colocando a hipótese de que a uma linguagem confusa tende a corresponder um pensamento confuso. Assim sendo, haverá a necessidade de se tornar independente os aspectos que na referida cifra representam a função tonal, as alterações à estrutura intervalar base da tríade, o uso de eventuais notas adicionais como a sétima e a nona, e a inversão em que a mesma se encontra, tendo em vista o clarificar e o objetivar da compreensão da harmonia tonal. Indo procurar falsear a referida hipótese com recurso a uma perspectiva vinda da linguística, dado estarmos perante uma relação signo - i.e., cifra harmônica - e significante - i.e., função harmônica percepcionada -, chego à conclusão de que não me é possível falsear a mesma, tendo que a aceitar como válida. Desta forma, e a título exemplificativo do aqui proposto, aplico este facto à análise harmônico-funcional do Lied Laß dich nur nicht dauern, opus 137, n.․ 9, de Max Reger. 


\section{Introdução}

No âmbito da música tonal, existem diversas formas de se cifrarem as harmonias utilizadas, nomeadamente no âmbito da chamada harmonia funcional, precursora da teoria funcional surgida com Riemann em 1887, a qual acaba por reduzir todas as funções tonais a somente três categorias de acordes: tônica, subdominante e dominante, i.e., T-S-D (Collura, 2006, p. 5). ${ }^{1}$ Entre as diversas formas de cifra harmônica em uso, o baixo cifrado e a tablatura podem ser utilizados para se representar as harmonias utilizadas no âmbito da dita música tonal, ${ }^{2}$ harmonias estas cuja construção está alicerçada na tríade enquanto unidade harmônica fundamental. Há igualmente outras formas de cifra em uso, como por exemplo no âmbito da música ligeira e do jazz, onde se usam as letras do alfabeto para se representar as fundamentais das tríades utilizadas, às quais se acrescentam alguns outros elementos, nomeadamente para se distinguir acordes perfeitos menores de acordes perfeitos maiores, bem como para indicar notas adicionais à referida tríade, como é o caso da sétima e/ou da nona. Contudo, nenhum destes três sistemas de cifra nos representa a estrutura funcional do respectivo acorde dentro da tonalidade necessidade esta que surge da adoção de uma análise harmônica funcional -, mas somente nos indica a fundamental do respectivo acorde - este é o caso da cifra alfabética em uso na música ligeira e no jazz -, a forma como deveremos proceder para tocar o respectivo acorde - este é o caso do baixo cifrado, o qual representa uma estrutura intervalar sobre uma nota escrita, ou da tablatura, a qual nos representa a forma como as cordas do violão ${ }^{3}$ deverão ser pisadas no braço do referido instrumento -, e ainda alguns outros aspetos deste, como seja, a sua estrutura intervalar, eventuais notas adicionais e, em alguns casos, a respectiva inversão. ${ }^{4}$

Há que salientar o facto de que nenhum destes três sistemas de cifra nos indica a função tonal do referido acorde, tendo esta que ser por nós aferida em função da tonalidade em que nos encontramos. Por exemplo, observemos as seguintes sequências harmônicas, descritas com uso do sistema de cifra alfabética e em duas tonalidades distintas, como a seguir discrimino:

\section{Dó Maior $\Rightarrow|\mathrm{C}| \mathrm{A}_{\mathrm{m}}\left|\mathrm{D}_{\mathrm{m}}\right| \mathrm{G}|\mathrm{C}| \mid$ \\ 2. Fá Maior $\Rightarrow|F| D_{m}\left|G_{m}\right| C|F| \mid$}

De facto, verificamos que entre estas duas sequências harmônicas encontramos dois acordes repetidos: $\mathrm{C}$ e $\mathrm{D}_{\mathrm{m}}$. Contudo, na primeira sequência, em Dó Maior, o acorde $\mathrm{C}$ representa

\footnotetext{
${ }^{1}$ Nesta ótica analítica, só se analisam três funções harmônicas (T-S-D), sendo que os acordes que não possam ser nestas enquadrados, são considerados como sendo essencialmente acordes de passagem, não sendo alvo de uma análise funcional. Esta é, pois, uma forma analítica de carácter redutor e que releva fundamentalmente a macroestrutura, em detrimento da respectiva microestrutura, harmônico-funcional.

${ }^{2}$ Neste caso, sem considerar a respectiva função tonal.

${ }^{3}$ Apesar de historicamente a tablatura ter sido também utilizada em instrumentos de tecla, hoje a mesma se restringe, no seu uso, a instrumentos de corda trasteados.

${ }^{4}$ Tanto o baixo cifrado como a tablatura são capazes de representar as três dimensões aqui referidas, a saber: [i.] a estrutura intervalar do acorde - i.e., se o referido acorde é menor, maior, diminuto, ou aumentado -, [ii.] eventuais notas adicionais ao mesmo - como sejam, a sétima e a nona -, [iii.] bem como a sua inversão - i.e., qual das notas que o constitui é a nota que soa como sendo a nota mais grave. Já a cifra baseada nas letras do alfabeto em geral só consegue representar as duas primeiras destas três dimensões, não representando assim a inversão do respectivo acorde, mas somente a sua estrutura intervalar e eventuais notas adicionais à tríade que constitui a sua base.
} 
uma função de tônica e o acorde $\mathrm{D}_{\mathrm{m}}$ uma função de sobretônica, enquanto que na segunda sequência, em Fá Maior, o acorde $\mathrm{D}_{\mathrm{m}}$ já representa a função de sobredominante e o acorde $\mathrm{C}$ a função de dominante da referida tonalidade. Ou seja, apesar destes dois acordes se repetirem nestas duas sequências harmônicas, a função de cada um deles em cada uma delas é distinta e depende do enquadramento tonal em que os referidos acordes são utilizados. Daí podermos concluir que não só a função tonal de um acorde é sempre dependente do contexto em que o mesmo se encontra inserido, como nenhum dos três sistemas de cifra até aqui referenciados nos permite representar a referida função tonal, função tonal esta que é sempre dependente do contexto onde um dado acorde é utilizado. Na verdade, podemos verificar que, numa harmonia funcional, como a que esteve em uso na música ocidental europeia entre os séculos XVII e XIX, existem quatro dimensões distintas e autônomas que são analiticamente relevantes, a saber: [i.] a estrutura intervalar do acorde; [ii.] o uso de eventuais notas adicionais; [iii.] a sua inversão; e [iv.] a função que o mesmo desempenha na respectiva estrutura tonal analisada (cf. Bochmann, 2003).

Historicamente falando, a necessidade de se representar a referida função, numa análise harmônica funcional, foi inicialmente resolvida juntando-se ao baixo cifrado um número em algarismos romanos representando a função tonal do acorde analisado. ${ }^{5}$ Assim, a função de tônica é representada por I, a função de sobretônica por II, a função de mediante por III, a função de subdominante por IV, a função de dominante por V, a função de sobredominante por VI, e a função de sensível ${ }^{6}$ por VII, podendo-se ainda recorrer ao uso de letras minúsculas para se representar acordes com terceira ${ }^{7}$ menor, e de letras maiúsculas para se representar acordes com terceira maior. ${ }^{8}$ Desta forma, pode-se usar o baixo cifrado para se representar a estrutura intervalar, eventuais notas adicionais e a inversão do respectivo acorde, adicionandose ao mesmo um número romano que representa a respectiva função tonal, na esteira do que Richter (1864) utilizou no seu Lehrbuch der Harmonie de 1853 (Collura, 2006, p. 4). Por exemplo, a sequência em Dó Maior de um acorde da tônica no seu estado fundamental, seguido de um acorde da dominante na sua primeira inversão, pode ser cifrada da seguinte forma: ${ }^{9}$

\footnotetext{
${ }^{5}$ Como as siglas alfabéticas se podem tornar confusas por serem em geral abreviaturas da respectiva designação linguística da função tonal em causa, o uso de uma designação numérica acaba por ser a mais aceite pela sua maior universalidade, sendo adotada desde o início do século XIX (Collura, 2006, p. 3). Contudo, para se evitar uma eventual confusão com o baixo cifrado, estas funções são designadas pelos algarismos romanos de I a VII, e não pela numeração árabe em uso no referido baixo cifrado. Tal prática veio ainda a permitir a combinação da indicação da função tonal, por um algarismo romano, com o uso simultâneo do baixo cifrado para indicar as outras três dimensões relevantes na harmonia tonal, i.e., a inversão usada, eventuais notas adicionais, e possíveis alterações à sua estrutura intervalar base. Segundo Collura (2006, p. 4), esta prática terá sido inicialmente introduzida no Lehrbuch der Harmonie de Richter (1864), publicado, na sua primeira edição, em 1853.

${ }^{6}$ Todas as funções aqui mencionadas se referem ao grau melódico da escala que serve de fundamental ao respectivo acorde, sendo que, por exemplo, a função de sensível, quando sob a forma de um acorde de quinta diminuta, só é efetivamente percebida como tal quando seguida de um acorde da mediante, num encadeamento vii - iii (Bochmann, 2003, p. 36).

${ }^{7}$ Terceira esta medida em relação à respectiva fundamental considerando que o acorde em causa está no seu estado fundamental.

${ }^{8}$ Neste caso, as referidas funções tonais serão representadas, no modo maior, por: I, ii, iii, IV, V, vi e iii, sendo que o traço sobre o vii se refere à quinta diminuta sobre a fundamental que caracteriza este acorde no referido modo maior, optado assim por uma simbologia similar à usada por Bochmann (2003).

${ }^{9}$ Aqui opto por colocar todas as alterações intervalares, de carácter descendente ou ascendente, antes do número que representa o intervalo harmônico cifrado. Contudo, historicamente as normas de escrita do baixo
} 


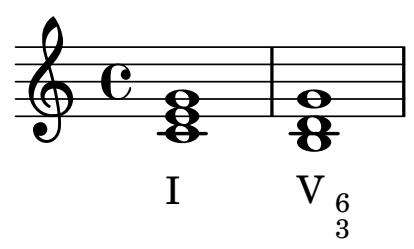

Contudo, se a referida sequência harmônica em causa for agora de um acorde de tônica na sua primeira inversão, seguido de um acorde de sétima da dominante na sua terceira inversão, então a sua análise já passará a ser apresentada como:

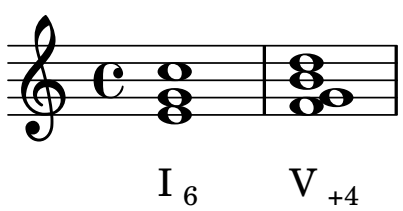

Mas, como podemos verificar, misturado numa mesma dimensão representacional do referido simbolo - aquela que é aqui representada pelo elemento simbólico advindo do baixo cifrado -, temos a representação de duas dimensões distintas: por um lado, a representação da inversão do referido acorde - no primeiro exemplo, o acorde da dominante está na primeira inversão, enquanto que, no segundo exemplo, o referido acorde está na terceira inversão -, e por outro lado, temos a representação de uma nota adicional de sétima sobre a fundamental do acorde em causa, i.e., do acorde da dominante no segundo exemplo acima apresentado.

Esta diferença analítica, não completamente análoga, entre o elemento simbólico escrito e o fenômeno auditivo percepcionado, pode-nos levar a um afastamento progressivo entre o signo e o significante. ${ }^{10}$ Desta forma, é minha intenção aqui questionar critérios que possam nos ajudar na escolha de um sistema de cifra harmônica mais adequado à realização de análises harmônicas funcionais no âmbito da linguagem tonal, ${ }^{11}$ e em que medida podemos justificar esta nossa escolha numa dimensão racional que nos permita realizar essa mesma análise de uma forma facilitada, mantendo uma estrita analogia entre a variância do signo e a variância do significante.

De facto, vou começar por discutir, no âmbito da literatura e da pesquisa linguística, até que ponto a representação simbólica de uma realidade nos pode condicionar a forma como percebemos essa mesma realidade, pondo a hipótese de que a uma linguagem confusa tende a corresponder um pensamento confuso. E, como no âmbito da linguagem tonal, na representação dos acordes analisados existem quatro dimensões distintas igualmente importantes - a saber, a sua estrutura intervalar, o uso de eventuais notas adicionais, a inversão do referido acorde, e a

cifrado são instáveis, havendo quem o coloque por cima, e não por baixo, da pauta musical, bem como quem coloque os acidentes antes ou depois do respectivo número consoante o intervalo harmônico em causa seja reduzido ou aumentado por estes. Há ainda que levar em conta que nem todos os intervalos harmônicos utilizados aparecem na respectiva cifra, havendo lugar a um processo de simplificação com a omissão de intervalos harmônicos que se presumem a partir dos intervalos harmônicos efetivamente cifrados (Pinho, 2002, pp. 79-84).

${ }^{10}$ Numa perspectiva semiótica, o signo é aqui constituído pelo simbolo analítico utilizado e o significante pela percepção auditiva da harmonia analisada.

${ }^{11}$ Sem querer com isso questionar a relevância e a pertinência das análises focadas principalmente na macroestrutura harmônico-funcional, penso ser igualmente importante analisar, em termos funcionais, todos os acordes numa harmonia tonal, abrangendo não só a referida macroestrutura, como também a sua microestrutura harmônico-funcional. 
função que o mesmo desempenha na estrutura tonal analisada -, questiono se o facto de duas ou mais destas dimensões serem representadas de uma forma unificada no referido símbolo, como acontece nos exemplos acima apresentados, pode contribuir para ofuscar a clareza necessária à compreensão de uma análise harmônica funcional, sobretudo quando a harmonia em causa se torna mais complexa e tonalmente instável, quer via cromatismo, quer via modulação, duas faces distintas de uma mesma dimensão que caracteriza a linguagem tonal: a afirmação de uma tonalidade central através do estabelecimento de uma relação de proximidade e de contraste com outras tonalidades próximas e/ou afastadas desta.

\section{O determinismo linguístico}

O determinismo linguístico, também chamado de hipótese Sapir-Whorf, afirma que os pensamentos são moldados pela relatividade linguística, sendo que as diferenças linguísticas, ao nível das suas estruturas lexicais e sintáticas, determinam diferenças nas estruturas de pensamento de seus falantes. Ou seja, segundo esta perspectiva teórica, a forma como pensamos é um reflexo direto da forma como falamos, o que, por sua vez, é fruto de um ambiente físico e cultural que nos é próprio, e que molda a forma como percepcionamos e compreendemos o mundo à nossa volta. Assim, o pensamento será um reflexo direto da nossa própria linguagem, a qual, por sua vez, é um reflexo do meio ambiente e cultural onde vivemos. Aliás, para Sapir, "a realidade é produzida pela linguagem, o que significa dizer que não há mundos iguais, visto que não há línguas iguais." (Severo, 2004, p. 128). Já no âmbito da etnolinguística, Whorf vai afirmar que na "língua hopi, [...] não é possível pensar o tempo de forma linear como em outras línguas, pois não há palavras, expressões ou formas gramaticais que permitam isso." (Severo, 2004, p. 129). Contudo, segundo Pinker (2002; 2015), tal afirmação de Whorf é equivocada, pois

em seu minucioso estudo sobre os Hopi, o antropólogo Ekkehart Malotki [...] mostrou $[. .$.$] que a fala dos Hopi contém tempos verbais, metáforas para tempo, uni-$ dades de tempo [...], maneiras de quantificar unidades de tempo e palavras como «antigo», «rápido», «muito tempo» e «terminado». [E] por métodos sofisticados, a cultura deles mantém registros de datas, inclusive um calendário solar baseado no horizonte, sequências exatas de dias sagrados, cordões com nós, paus com entalhes, que servem de calendário, e vários instrumentos para medir o tempo usando o princípio do quadrante solar (Pinker, 2015, p. 7).

Pinker (2015) termina, dizendo que "ninguém sabe com certeza de onde Whorf tirou suas estranhas armações, mas sua amostra limitada e mal analisada da fala Hopi, e sua velha afeição pelo misticismo devem ter contribuído." (Pinker, 2015, p. 7).

No entanto, a afirmação de que existe uma ligação entre o pensamento e a linguagem não é exclusiva de Sapir e Whorf, sendo a mesma encontrada em outros autores, como é o caso de Lev Vygotsky, o qual "aborda a importância [...] [dessas] relações interfuncionais [...], relações essas que, a seu ver, estudos anteriores não conseguiram desenvolver com propriedade 
por entenderem pensamento e fala como funções isoladas." (Brites \& Cássia, 2013, p. 179). Assim, para Vigotsky (1987), esta relação entre pensamento e linguagem não corresponde a um elo direto e primário, mas antes a uma conexão complexa que se desenvolve ao longo da evolução de ambos, sendo que o progresso da fala não é inteiramente paralelo ao progresso do pensamento. Contudo, para o referido autor, o desenvolvimento do pensamento não deixa de ser um reflexo da linguagem e da experiência sociocultural da criança, pelo que podemos afirmar que, pensamento e linguagem, interagem entre si de uma forma não inteiramente linear, condicionando-se mutuamente um ao outro.

Severo (2004) apresenta-nos ainda outros dois autores que contribuíram para a definição da "hipótese determinística no que concerne à maneira pela qual linguagem e sociedade podem se implicar" (Severo, 2004, p. 127). Estes dois autores são Hymes e Labov, sendo que o primeiro "pauta a sua teoria no pressuposto da linguística constituída socialmente" (Severo, 2004, p. 130), e o segundo "propõe «o estudo da estrutura e da evolução da língua dentro do contexto social da comunidade de fala»." (Severo, 2004, p. 131). Desta forma, tanto Hymes como Labov vão desenvolver os seus estudos linguísticos no pressuposto de que existe uma relação intrínseca entre linguagem e pensamento, interligando uma determinada língua a uma cultura que lhe é própria e específica, cultura esta dentro da qual essa mesma língua emerge e se desenvolve.

De facto, apesar de não ser meu objetivo aqui adentrar em considerações profundas no âmbito da linguística, só com base nestas escassas referências já nos é possível afirmar que há estudos que estabelecem uma relação de interdependência entre pensamento e linguagem, mesmo que complexa e não tão linear quanto Whorf procurou afirmar na sua interpretação errônea da língua hopi. E, mesmo fora do âmbito estrito da linguística, Vigotsky (1987) já nos alertava para a existência de algum tipo de relação entre o desenvolvimento da linguagem e do pensamento na criança, mesmo que essa relação possa não ser completamente linear como os autores do determinismo linguístico inicialmente nos propuseram. Agora, apesar das objeções apresentadas por Pinker $(2002 ; 2015)$, não nos é possível refutar a hipótese de que existe uma relação, não linear, complexa e de influência mútua, entre linguagem e pensamento, pelo que a referida hipótese se mantém como válida. Aliás, mesmo as críticas de Pinker não são suficientes para refutar por completo a ideia fundamental que está subjacente ao determinismo linguístico, somente complexificando a natureza da relação de interdependência entre pensamento e linguagem, introduzindo um nível adicional de complexidade relativo às estruturas mentais sobre as quais o nosso pensamento opera. Contudo, essas estruturas mentais representam e são representadas pela linguagem que utilizamos, pelo que se acaba por estabelecer uma relação, mesmo que indireta, entre pensamento e linguagem.

Desta forma, a hipótese que comecei por colocar, de que uma linguagem confusa tende a corresponder a um pensamento confuso, não deixa de poder encontrar suporte nestas considerações teóricas, mesmo que, como é normal em toda a natureza humana, esta seja uma relação complexa e nem sempre tão linear como a hipótese Sapir-Whorf a princípio nos determinaria. Mas mesmo de forma empírica, é nos possível lembrar de exemplos onde uma linguagem confusa surge paralelamente a um pensamento confuso que lhe parece estar subjacente, mesmo 
que isso não nos permita determinar imediatamente, e por si só, uma relação de nexo de causalidade. Assim, mesmo reconhecendo a complexidade desta relação, não nos é possível negar a existência de algum reflexo da forma como pensamos na forma como falamos, e vice-versa, pelo que um pensamento objetivo e claro tenderá a estar muito provavelmente acompanhado de uma linguagem objetiva e clara. E quais são as implicações disso para a dita análise harmônica funcional? A meu ver, essas implicações residem no facto de que a simbologia analítica utilizada deve, tanto quanto possível, expressar de forma objetiva e autônoma cada uma das dimensões relevantes no referido sistema linguístico-musical, pelo que, aspectos como a função tonal, a inversão, as alterações intervalares, e as notas adicionais à tríade, devem estar refletidas em elementos específicos do símbolo analítico utilizado, o que nos ajudará a uma compreensão autônoma de cada uma destas quatro dimensões, ao mesmo tempo que facilitará o nosso pensamento em torno da referida análise harmônica de carácter funcional.

\section{Simbologia analítica}

Colocadas estas considerações iniciais, há ainda que esclarecer que admito não haver um sistema de cifra harmônica ideal para todas as situações. Por exemplo, as necessidades do intérprete no uso e leitura de cifras harmônicas são distintas das necessidades do teórico que usa os respectivos símbolos como representação conceptual e como auxílio à compreensão das estruturas harmônicas por ele analisadas, nomeadamente aquelas que estão subjacentes a uma harmonia de carácter funcional. Neste sentido, ao instrumentista interessa, em primeiro lugar, saber quais os gestos e ações motoras que o seu corpo tem de empreender sobre um dado instrumento musical para que este produza o som que lhe é solicitado pela respectiva partitura. Neste domínio, dependendo das épocas e dos estilos musicais em causa, o baixo cifrado e/ou a tablatura podem ser meios ideais para esse fim. Mas quando o objetivo é tentar compreender, do ponto de vista funcional, uma dada estrutura harmônica, o que passa a ser mais relevante já não é a forma como se toca a referida harmonia em um qualquer instrumento musical, mas os conceitos e dimensões que são específicos e essenciais à linguagem musical analisada. E se no tonalismo, considerando grosso modo a música tonal produzida na cultura ocidental europeia entre os séculos XVII e XIX, a importância conceptual reside em torno das quatro dimensões já atrás mencionadas, ${ }^{12}$ então o nosso símbolo analítico deverá reproduzir cada uma dessas dimensões de uma forma tão autônoma quanto possível, atendendo à hipótese de que existe uma relação intrínseca entre a clareza da representação simbólica utilizada e a clareza e objetividade do nosso pensamento. Desta forma, a proposta de cifra apresentada por Richter (1864) não é a mais adequada, uma vez que esta mistura num único elemento ${ }^{13}$ três destas quatro dimensões, deixando para um outro elemento autônomo a dimensão aí em falta. ${ }^{14}$

Por outro lado, a proposta apresentada por Riemann (1896) é algo redutora nas funções

\footnotetext{
${ }^{12}$ A saber: a função tonal, a inversão, as alterações intervalares, e as notas adicionais à tríade.

${ }^{13}$ Constituído por algarismos árabes seguindo a convenção do baixo cifrado.

${ }^{14} \mathrm{~A}$ única dimensão representada de forma autônoma é a função tonal, a qual é representada através de um número romano.
} 
tonais evidenciadas, ao basicamente fazer sobressair somente três destas funções (T-S-D) (cf. Collura, 2006; Taddei, 2012), não deixando assim propriamente espaço para a consideração de outras funções tonais que, apesar de serem menos relevantes do que estas três funções estruturantes da tonalidade, não podem ser consideradas como inexistentes em exemplos harmonicamente mais ricos, como acontece, por exemplo, em algumas obras de Johann Sebastian Bach $(1685$ - †1750). De facto, quando, por exemplo, se faz suceder a um acorde diminuto sobre o sétimo grau da escala, um acorde perfeito menor sobre o seu terceiro grau, as funções tonais audíveis não são inseríveis em qualquer uma das referidas funções de tônica, subdominante ou dominante. Desta forma, mesmo aceitando a hipótese de que auditivamente podemos não ser capazes de perceber sete funções tonais distintas - tantas quanto os graus melódicos de uma escala maior ou menor -, seremos contudo sempre capazes de perceber, pelo menos em determinados contextos, mais do que as referidas três funções tonais de tônica, subdominante e dominante. Assim, precisaremos de um sistema que seja robusto na possibilidade de representar mais do que estas três funções - como acontece em Richter (1864) -, mas que ao mesmo tempo mantenha uma representação autônoma, ao nível da respetiva representação simbólica, de cada uma das já citadas quatro dimensões tonais, à semelhança do que propõe Bochmann (2003).

Retornando, pois, aos dois exemplos de sequências harmônicas anteriormente apresentados na página 4, poderemos então propor uma outra análise para os mesmos, pondo em prática as considerações aqui apresentadas:
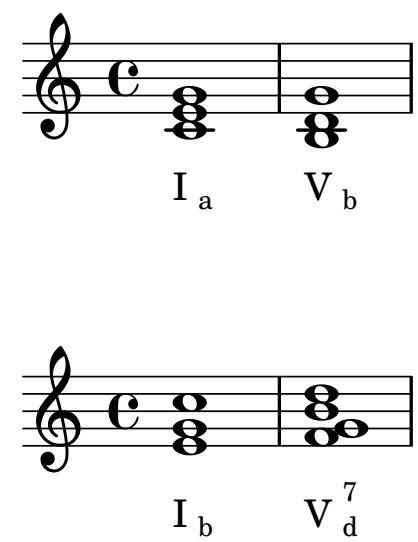

Nestas duas novas propostas de análise, não só a variabilidade dos respectivos signos é mais análoga à variabilidade da nossa percepção auditiva quando comparada com a proposta de análise anteriormente apresentada na página 4, como cada uma das quatro dimensões referenciadas para a harmonia analisada tende a se refletir em elementos distintos da simbologia analítica utilizada. $^{15}$

\footnotetext{
${ }^{15}$ Por razões que se prendem com restrições impostas pelo $\mathrm{LAT}_{\mathrm{E}} \mathrm{X}$ - linguagem de processamento de texto em que este artigo está sendo escrito -, no exemplo de análise harmônica, a seguir apresentado, farei algumas adaptações à proposta de cifra harmônica apresentada por Bochmann (2003), mantendo no entanto a autonomia na representação simbólica das citadas quatro dimensões tonais.
} 


\section{Exemplo de análise harmônica}

Vou agora colocar em prática as considerações teóricas até aqui apresentadas, analisando harmonicamente o Lied Laß dich nur nicht dauern de Max Reger (1873 - †1916) (Reger, 1914), apresentado na página seguinte. Em termos tonais, este Lied está em Sol Maior, sendo que o quadro abaixo resume a relação entre esta sua tônica de Sol Maior e as tonalidades que lhe são mais próximas, i.e., aquelas que se distanciam até um acidente a mais (quinta acima) ou a menos (quinta abaixo) na respectiva armadura de clave:

\begin{tabular}{|c|c|c|}
\hline Dó Maior $(\mathrm{S})^{16}$ & Sol Maior $(\mathrm{T})^{17}$ & Ré Maior $(\mathrm{D})^{18}$ \\
\hline Lá menor $(\mathrm{rS})^{19}$ & Mi menor $(\mathrm{rT})^{20}$ & Si menor $(\mathrm{rD})^{21}$ \\
\hline
\end{tabular}

Assim, esta análise funcional harmônica da sua primeira frase - i.e., da anacruse para o primeiro compasso até ao terceiro tempo do terceiro compasso -, pode ser apresentada como: ${ }^{22}$

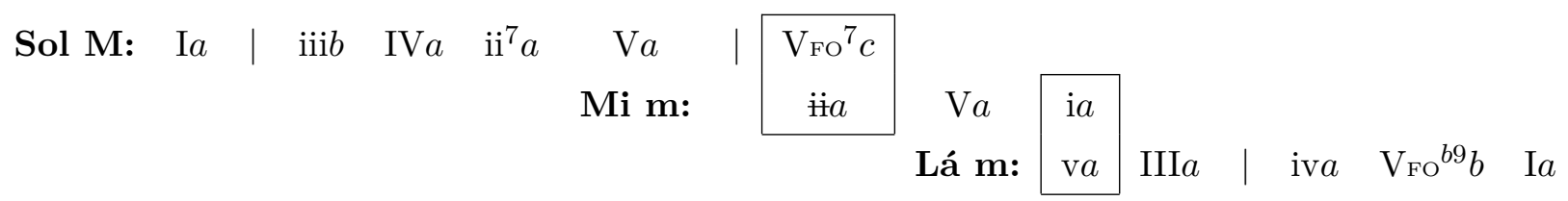

Nesta análise aqui efetuada, temos o uso do conceito, proposto por Bochmann (2003, pp. 6970 ), de acorde sem fundamental, como analisado no primeiro tempo do segundo compasso e no segundo tempo do terceiro compasso, normalmente utilizado em acordes de sétima ou nona com função de dominante primária (por exemplo, $\mathrm{V}_{\mathrm{FO}}^{7} c$ ) ou secundária (por exemplo, $\mathrm{II}_{\mathrm{FO}}{ }^{7} c$ ). Este conceito se destina a preservar analiticamente a função auditivamente percebida, a qual não corresponde à fundamental do acorde efetivamente utilizado, sendo que em geral a sequência de um acorde diminuto e de um outro acorde com fundamental uma segunda acima deste, tende auditivamente a ser entendido como uma relação dominante/tônica dada a resolução do intervalo harmônico de trítono - i.e., de quinta diminuta ou de quarta aumentada -, num intervalo harmônico de terceira ou de sexta. ${ }^{23}$

Na análise deste trecho, há ainda alguns outros aspectos a salientar:

1. Os acordes de transição entre duas tonalidades, a que Bochmann (2003) chama de acordes pivot, tendem a ter uma função relevante na tonalidade de onde vimos, em geral de tônica

\footnotetext{
${ }^{16}$ Subdominante.

${ }^{17}$ Tônica.

${ }^{18}$ Dominante.

${ }^{19}$ Relativo da subdominante.

${ }^{20}$ Relativo da tônica.

${ }^{21}$ Relativo da dominante.

${ }^{22}$ Aqui utilizo um sistema de simbologia analítica similar ao proposto por Bochmann (2003), mas com algumas adaptações visando facilitar a sua escrita em $\mathrm{ATT}_{\mathrm{E} X}$. Assim, acordes com fundamental omitida (Bochmann, 2003, pp. 69-70) são indicados com as iniciais Fo (por exemplo, $\mathrm{VFO}^{7} c$ ) após o respectivo grau funcional, acordes perfeitos menores são grafados com o grau funcional em letra minúscula (por exemplo, iiia), e acordes perfeitos maiores são grafados com o grau funcional em letra maiúscula (por exemplo, Ia). Já os acordes diminutos terão um traço horizontal sobreposto ao respectivo grau funcional escrito em letra minúscula (por exemplo, i̇a).

${ }^{23} \mathrm{~A}$ quinta diminuta se resolve num intervalo harmônico de terceira e a quarta aumentada num intervalo harmônico de sexta.
} 
Figura 1: Lied Laß dich nur nicht dauern (Reger, 1914, p. 9)

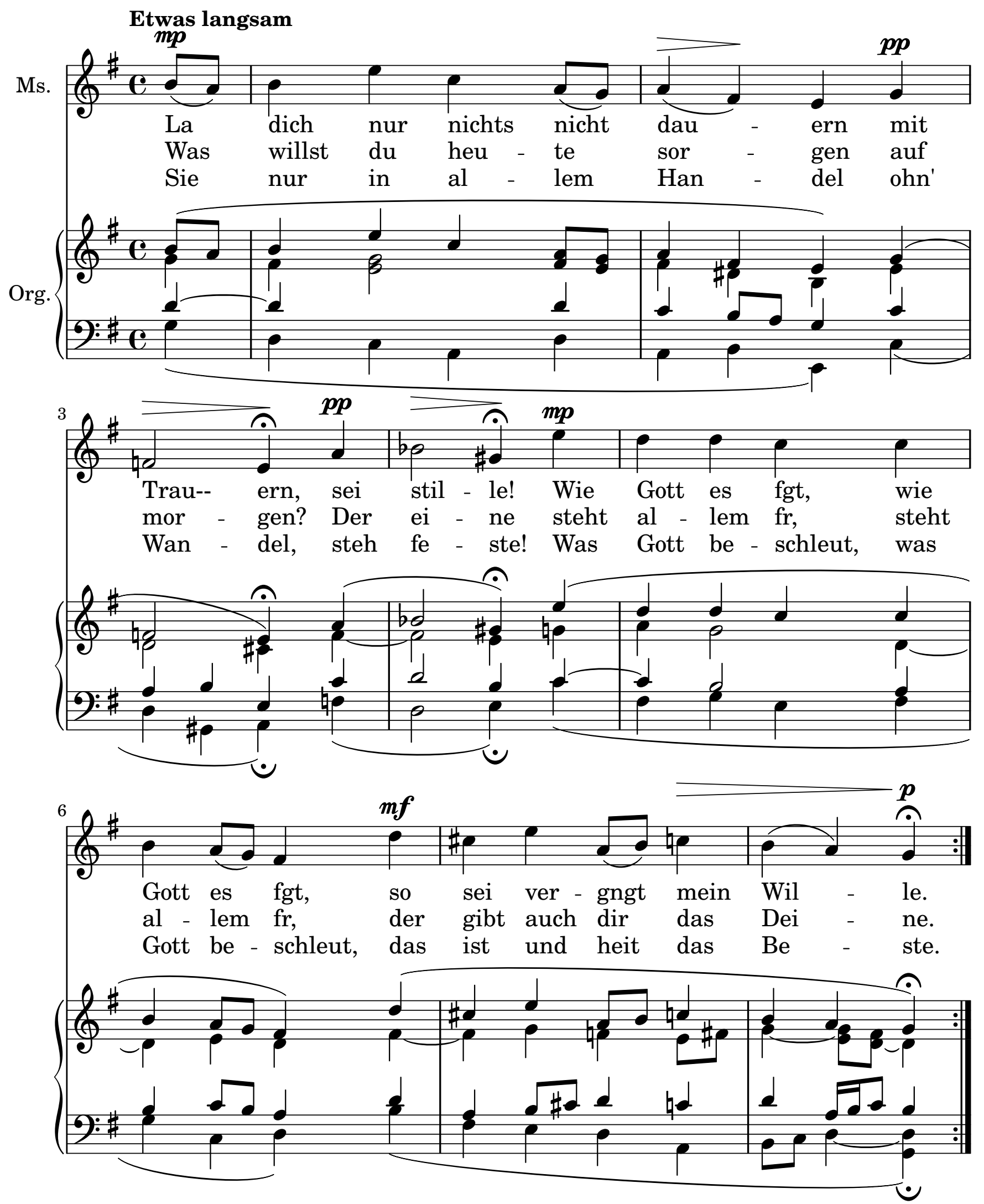


ou de dominante, mas podem assumir uma qualquer função na tonalidade para onde modulamos (ver acima o que sucede, na análise proposta, no primeiro e terceiro tempo do segundo compasso);

2. Nos acordes com sétima, presume-se que a mesma é sempre diatônica dentro da tonalidade em que nos encontramos, só sendo indicada uma eventual alteração a esta se a mesma divergir desta regra. Por exemplo, o acorde $\mathrm{I}^{7} a$ terá uma sétima maior, mas o acorde $\mathrm{V}^{7} a$ já terá uma sétima menor (no primeiro caso, se pretendermos simbolizar um acorde com sétima menor, colocaremos um bemol antes do sete, i.e., analisaremos como $\mathrm{I}^{b 7} a$, o qual se transformará desta forma num acorde de dominante da subdominante em relação à tônica em que nos encontramos);

3. Já nos acordes de nona, não só os mesmos pressuporão a existência de uma sétima, como a nona será sempre entendida como sendo maior ${ }^{24}$ - e isto independentemente do intervalo diatônico formado sobre a fundamental do respectivo acorde analisado -, pelo que $\mathrm{V}^{9} a$ indicará sempre um acorde com nona maior e $\mathrm{V}^{b 9} a$ um acorde com nona menor;

4. Por último, as regras aplicáveis ao modo maior, com reflexo no simbolo analítico utilizado, terão sempre primazia relativamente ao modo menor, tendo em vista o evitar que um mesmo simbolo possa ter mais do que um significado analítico. Por exemplo, no modo menor, $\mathrm{i}^{7} a$ representará sempre um acorde de tônica com sétima maior e $\mathrm{i}^{b 7} a$ um acorde de tônica com sétima menor, independentemente do facto da referida sétima recair numa nota que é melodicamente móvel no modo menor. Contudo, no acorde da dominante no referido modo menor, já não haverá esse mesmo problema pois a sétima diatônica sobre a fundamental será, neste caso, sempre menor.

Continuando a análise harmônica do referido Lied, a partir do quarto tempo do terceiro compasso até ao terceiro tempo do sexto compasso, temos:

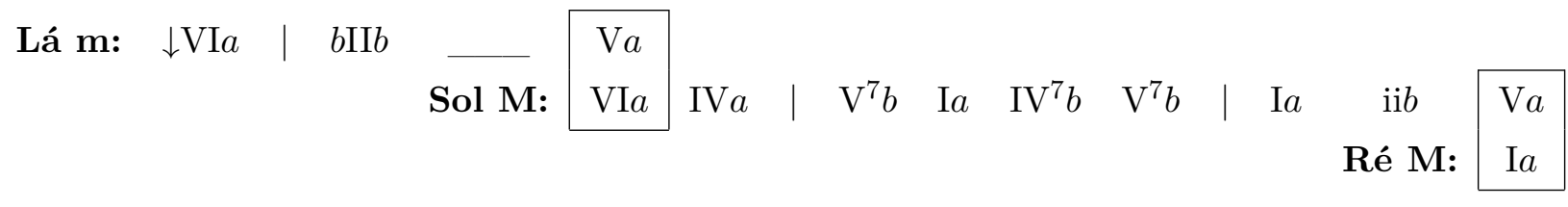

e do quarto tempo do sexto compasso até ao terceiro tempo do oitavo compasso, temos:

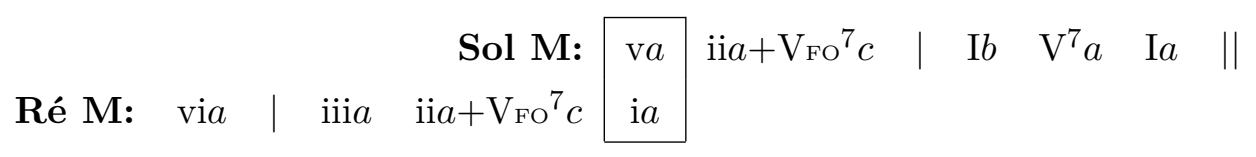

\footnotetext{
${ }^{24} \mathrm{~A}$ razão para este pressuposto se deve à necessidade de evitar que um mesmo símbolo analítico possa representar duas estruturas intervalares distintas. Por exemplo, se não considerarmos a regra aqui proposta, o acorde $\mathrm{V}^{9} a$ poderia ter uma nona maior ou uma nona menor, no modo menor, dependendo da versão que viesse a ser utilizada, ascendida ou descendida, do sexto grau melódico da escala. E como devemos evitar a polissemia dos símbolos analíticos utilizados tendo em vista a necessária objectividade na relação signo/significante, tornase indispensável aqui impor uma regra distinta do que acontece com a sétima de um acorde, a qual poderá ser sempre considerada em função do seu intervalo diatônico, pois no modo menor $\mathrm{V}^{7} a$ terá sempre uma sétima menor independentemente da mobilidade do sexto grau melódico do modo menor.
} 
concluindo assim o Lied em análise (Reger, 1914, p. 9).

Apesar da harmonia aqui usada por Max Reger possuir uma significativa simplicidade no uso da respetiva tonalidade e seus tons próximos (ver tabela com os mencionados tons próximos na página 9), no terceiro tempo do sétimo compasso, o uso de um acorde de tônica de Ré menor (ia), em vez de um acorde de tônica de Ré Maior (I $a$ ), pode nos dar a sensação de que momentaneamente modulamos ao relativo da subdominante da subdominante, em vez de à dominante. $\mathrm{Na}$ verdade, sendo ambas as interpretações eventualmente admissíveis, Reger não se distância aqui de uma prática já encontrada em Johann Sebastian Bach (1685 - †1750), não podendo por isso a mesma ser considerada inovadora. Também no segundo e quarto tempos do sétimo compasso, temos a sucessão de um acorde de sobretônica no estado fundamental (ii a) e de um acorde de sétima da dominante sem fundamental na segunda inversão $\left(\mathrm{V}_{\mathrm{FO}}{ }^{7} c\right)$, dominante esta que é criada pela condução melódica que ocorre respetivamente, na parte do acompanhamento, no tenor (nota de Dó\#) e no contralto (nota de Fá\#), conduzindo sucessivamente as sensíveis de Ré Maior e de Sol Maior para as respetivas tônicas.

\section{Conclusão}

No percurso até aqui percorrido, comecei por fazer algumas considerações relativas ao surgimento da análise harmônica funcional, ao mesmo tempo que me afastei de Riemann (1896), pois considero ser redutora a proposta que o mesmo apresenta ao considerar somente as funções tonais de tônica, subdominante e dominante. E isso é especialmente verdadeiro quando consideramos a riqueza harmônico-funcional existente em algumas obras musicais do Período Barroco (ca. 1600 a 1750), em especial da primeira metade do século XVIII. De facto, no referido repertório é nos possível percepcionar auditivamente mais do que as três funções tonais básicas propostas por Riemann, mesmo que seja questionável até que ponto somos efetivamente capazes de percepcionar auditivamente sete funções tonais distintas correspondentes aos sete graus melódicos da escala. Mas, por certo, as funções tonais audíveis são mais do que as referidas funções de tônica, subdominante e dominante, como por exemplo acontece a quando do uso da sequência harmônica viìb $\rightarrow$ iii $a$, onde o acorde vii não consegue ser assimilado à função de dominante dado que o mesmo não é seguido de uma função de tônica.

E, recorrendo à linguística, dado a representação simbólica da função harmônica do acorde ser uma representação abstrata de uma realidade auditiva - uma relação entre signo (cifra harmônica) e significante (função tonal percepcionada) -, também não nos é possível refutar a hipótese de que uma linguagem confusa tende a corresponder a um pensamento confuso, ao mesmo tempo que uma linguagem simples e clara tende a proporcionar uma compreensão clara e objetiva do objeto analisado. Desta forma, a referida hipótese mantém-se como válida, o que implica no facto de que, havendo na harmonia funcional quatro dimensões distintas e autônomas que são analiticamente relevantes - a saber: a função tonal, a estrutura intervalar do acorde, o uso de eventuais notas adicionais à tríade, e a sua inversão -, temos a necessidade 
de usar um sistema de cifra harmônica que preserve a autonomia da representação, de cada uma destas quatro dimensões, no signo analítico utilizado.

De facto, constatamos que é isso que Bochmann (2003) nos propõe, apesar de não apresentar uma justificação teórica para a simbologia analítica utilizada. Assim, pode-se concluir que, numa análise harmônica funcional que se queira microestrutural - i.e., que explicite a função tonal de todos os acordes utilizados -, é aconselhável o uso de uma simbologia analítica que represente autonomamente cada uma das referidas dimensões, procurando desta forma preservar uma relação de analogia entre a variância do simbolo analítico utilizado e a função tonal percepcionada em termos auditivos. Desta forma, uma análise de viii $b \rightarrow \mathrm{I} a$ deixa de fazer sentido ao não reter, na variância da respectiva cifra harmônica utilizada, uma variabilidade idêntica à percebida auditivamente relativamente a $\mathrm{V}_{\mathrm{FO}}{ }^{7} c \rightarrow \mathrm{I} a$ quando comparamos ambas com $\mathrm{V} c \rightarrow \mathrm{I} a .^{25}$ Na verdade, sem o justificar teoricamente, a proposta de cifra harmônica apresentada por Bochmann (2003) acaba por ser aquela que melhor responde à necessidade de clareza e objetividade no pensamento analítico em termos harmônico-funcionais, ao mesmo tempo que retém uma estreita analogia na variância entre o simbolo utilizado e a percepcionalidade auditivo-funcional da harmonia analisada.

\section{Referências}

Bochmann, C. (2003). A linguagem harmónica do tonalismo. Lisboa: Juventude Musical Portuguesa.

Brites, I. \& Cássia, R. (2013). Recensão: Vigotsky, L. (2005). Pensamento e linguagem. Revista Lusófona de Educação, (22), 179-184.

Collura, T. (2006). Apostilha do curso de hamonia funcional: parte I. Victória, ES: FAMES.

Pinho, J. F. B. D. (2002). Quadro teórico do baixo contínuo em Portugal no século XVIII. Dissertação de Mestrado, Universidade de Coimbra, Faculdade de Letras, Coimbra.

Pinker, S. (2002). O instinto da linguagem: como a mente cria a linguagem. São Paulo, SP: Martins Fontes.

Pinker, S. (2015). A linguagem molda o pensamento? Utopia <http://antiutopia.space $>$. Disponível em: <http://antiutopia.space/pinker-linguagem-molda-o-pensamento/>.

Reger, M. (1914). Zwölf geistliche Lieder: für eine Singstimme mit Begleitung von Klavier, Harmonium oder Orgel, op. 13\%. C. F. Peters.

Richter, E. F. (1864). Treatise on harmony. London: J. B. Cramer. Translated by Franklyn Taylor.

\footnotetext{
${ }^{25}$ Isto porque a sequência harmônica $\rightarrow \mathrm{I} b$ é na verdade percebida auditivamente como sendo uma relação funcional dominante/tônica.
} 
Riemann, H. (1896). Harmony simplified. London: Augener.

Severo, C. G. (2004). Linguagem e sociedade: algumas reflexções sobre determinismo. Working Papers em Linguística, (8), 127-140.

Taddei, R. C. (2012). A teoria de Hugo Riemann: além da harmonia simplificada ou funções tonais dos acordes. In Anais do II SIMPOM (pp. 1313-1320).

Vigotsky, L. S. (1987). Pensamento e linguagem. São Paulo, SP: Martins Fontes. 